\title{
Complexity Study of the Credit Risk of a Business Group
}

\author{
Yang Yang, ${ }^{1}$ Jing Gu, ${ }^{2}$ and Zongfang Zhou ${ }^{1}$ \\ ${ }^{1}$ College of Management and Economics, University of Electronic Science and Technology of China, Chengdu 610054, China \\ ${ }^{2}$ School of Economics, Sichuan University, Chengdu 610064, China \\ Correspondence should be addressed to Jing Gu; gj0901@scu.edu.cn
}

Received 25 March 2015; Accepted 31 May 2015

Academic Editor: Taher Lotfi

Copyright (C) 2015 Yang Yang et al. This is an open access article distributed under the Creative Commons Attribution License, which permits unrestricted use, distribution, and reproduction in any medium, provided the original work is properly cited.

\begin{abstract}
A business group is a complex system; thus it is much more difficult to predict its credit risk than that of an individual company. This study proposes an iterative model, which describes the internal interactions and dynamic credit risk of a business group. The proposed model was analyzed from a complex dynamics perspective. The simulation results based on this model show that chaos will emerge in the credit risk of a business group due to the dynamic decision-making processes of its subsidiaries, even if the interactions in the business group are fairly simple. The results of this study might explain some economic phenomena, and they also provide insights into the credit risk of a business group.
\end{abstract}

\section{Introduction}

With the continuous development of economic globalization, business groups play increasingly important roles in economic activities and are prevalent around the world (e.g., $[1,2])$. Because of the scale advantages of business groups, attempts by banks to attract business groups by providing favorable rates and flexible policies have been a tremendous success in the past two decades. Many banks have gained sizable benefits from their business group customers (e.g., [3, 4]). However, the worldwide financial crisis in 2008, and subsequent bankruptcy of numerous business groups, demonstrate that banks can never afford to ignore the importance of the credit risk of business groups. Thus, the need for credit risk control by banks with business group customers has never been as urgent as it is at present. Compared with individual companies, the credit risk of business groups is always much more complex and often unpredictable in reality. But why should this be the case? Why is it difficult to predict credit risk for business groups? What is the mechanism that underlies the evolution of the credit risk of a business group? This study attempts to answer these questions by constructing a mathematical model, conducting numerical simulations, and performing a dynamic system analysis. We argue that chaos will occur in the credit risk of a business group as time passes.

In recent years, increasingly close attention has been paid to the credit risk of business groups. Siegel and Choudhury
[5] argued that business groups have a relatively low credit risk compared with individual companies. Subsidiaries with limited access to intermediate funds in business groups can benefit from the support of the rest of group when they suffer negative cash-flow shocks. Gopalan et al. [6] and Khanna and Yafeh [7] found that the internal capital market in a business group can decrease the level of credit risk for its subsidiaries. These conclusions are also consistent with the view of Masulis et al. [8] who stated that the financing advantages of business groups outweigh their disadvantages. By contrast, some researchers have stated the opposite opinion, where they suggest that the credit risk of business groups is often higher than that of individual companies because of tunneling (e.g., $[9,10])$. In addition, other studies have demonstrated that whether the credit risk of subsidiaries affiliated with business groups is lower than that of individual companies depends on a variety of parameters (e.g., [11, 12]). In general, the inconsistent conclusions of previous studies suggest that the credit risk of business groups is complex. Chen and Zhou [13] developed a method to measure the credit risk of business groups based on a structural model. Many studies have analyzed the default correlation using copula functions (e.g., [14-16]). Although these studies are significant, they still fail to explain the complexity of the credit risk of business groups.

In addition, many major economic events, such as the collapse of Barings Bank, the failure of China Aviation Oil (Singapore), the Enron scandal, and the bankruptcy petition 
of General Motors, serve as reminders that the credit risk of business groups is sensitive, and a butterfly effect may exist in the credit risk of a business group. We, therefore, constructed a newsvendor model, which is a fairly simple method, to describe the interactions among the subsidiaries of a business group. Next, we analyzed the complexity of the credit risk of the business group based on numerical simulations and a dynamic systems analysis of the model. The results of this study show that the credit risk of business groups leads to chaos even if the interactions within the business group are very simple. Our results also provide new insights into credit risk management for business groups.

The remainder of this paper is organized as follows. In the next section, we construct a model using discrete dynamics to describe the credit risk of a business group and find the Nash equilibrium point of credit risk with a given set of parameters. The emergence of chaos in the credit risk of a business group is demonstrated in Section 3 based on a numerical simulation and stability analysis. Section 4 provides the conclusions of this study.

\section{Model Construction and Analysis}

The model we constructed in this study was as concise as possible. This iterative model shows that credit risk for business groups can be complex and unpredictable, even if the interaction among their subsidiaries is described in a very simple manner.

2.1. Assumptions and Nomenclature. Following Jarrow and Turnbull [17], Ha and Tong [18], Chen and Bell [19], and Wang and $\mathrm{Ma}[20]$, the specific assumptions and notations of the proposed model are summarized as follows.

(1) The business group in our model is assumed to comprise $n$ subsidiaries, which are independent decision makers with the goal of profit maximization.

(2) The products of all the subsidiaries are perishable. Each subsidiary faces a newsvendor-type demand market. We assume that the demand of any subsidiary $i, \tilde{d}_{i, t}$ follows the uniform distribution $U\left[0,2 a_{i, t}\right]$, where $a_{i, t}$ represents the effort level selected by subsidiary $i$ in period $t$.

(3) To describe the collaboration and interactions among subsidiaries in the business group, we simply assume that the market price $P_{t}$, which depends on the total effort level, is the same for all the subsidiaries:

$$
P_{t}=\alpha+\beta S_{t}-\gamma S_{t}^{2}
$$

where $S_{t}=\sum_{i=1}^{n} a_{i, t}$.

(4) Each subsidiary $i$ has a nonlinear cost function, $C_{i, t}$, for their effort level. The subsidiaries always make the optimal effort level decision to obtain the maximum margin of profit in every period:

$$
C_{i, t}=m_{i}+n_{i} a_{i, t}+q_{i} a_{i, t}^{2} .
$$

(5) During each period, the business group has a fixed financial cost $D$, which is used to repay its external debt. If the total profit of the business group is lower than $D$ in any period, the business group will default. In this study, the probability of default is used to describe the credit risk of the business group.

The assumptions given above imply three intuitive conclusions. First, increasing the effort level can improve the demand market and increase the expected demand. Thus, the expected demand will be higher when the level of effort selected by the subsidiary is also higher. However, a high effort level can lead to a higher cost. Furthermore, a very high level of effort may also decrease the profit of other subsidiaries, because of the relatively low market price. Second, the market price is decided jointly by all the subsidiaries of the business group, which can affect the profits of all the subsidiaries. Third, the uncertainty in our model only originates from market demand. The volatility of demand directly affects the credit risk of the business group. The pattern of the business group we consider is similar to a modularized monopoly structure, which has the shape of horizontal integration and the character of competition. However, if we interpret the variable $a_{i, t}$ as the production decision making and interpret the formula (1) as the nonlinear inverse demand function of subsidiary $i$ in period $t$, we can probably explain these assumptions in the context of the supply chain.

To simplify the model, the influence on the subsidiaries due to the actual controller and the internal tunneling problem of the business group are not considered. Each subsidiary pursues its own profit maximization strategy and does not care about the overall welfare of the business group, even though the decisions of each subsidiary affect the other subsidiaries in the business group.

2.2. Model Construction. We define $\pi_{i, t}$ as the profit of subsidiary $i$ in period $t$ :

$$
\pi_{i, t}=P_{t} \tilde{d}_{i, t}-C_{i, t} .
$$

According to the assumptions in the previous section, the subsidiaries of the business group are independent and pursue their own profit maximization strategies. When the subsidiaries decide their effort level, they tend to increase their effort until the expected marginal revenue is equal to the marginal cost. Therefore,

$$
\begin{aligned}
\frac{\partial E\left[\pi_{i, t}\right]}{\partial a_{i, t}}= & -\gamma S_{t}^{2}+\beta S_{t}+\beta a_{i, t}-2 \gamma a_{i, t} S_{t}-2 q_{i} a_{i, t}+\alpha \\
& -n_{i} .
\end{aligned}
$$

The optimal effort level might not be achieved in every period because of the information asymmetry among the subsidiaries and the bounded rationality of decision makers. The subsidiaries should adjust their effort level in period $t+1$ according to their performance in period $t$. A strategy that the subsidiaries are highly likely to adopt in the dynamic decision-making process is marginal adjustment, to achieve 
the aim of profit maximization. This strategy could be represented by the following iterative equation:

$$
a_{i, t+1}=a_{i, t}+k_{i} a_{i, t}\left[\frac{\partial E\left[\pi_{i, t}\right]}{\partial a_{i, t}}\right],
$$

where $k_{i}$ is the adjustment coefficient for subsidiary $i$. In our model, this coefficient reflects the flexibility of the subsidiaries. The subsidiaries with higher adjustment coefficients may respond more vigorously to market changes compared with the subsidiaries with relatively lower adjustment coefficients. The coefficient can also be regarded as a measure of the individual characteristics of different decision makers. The subsidiaries that are controlled by radical decision makers tend to have higher adjustment coefficients, whereas the subsidiaries that are controlled by conservative decision makers tend to have lower adjustment coefficients. Since the adjustment coefficient vector $\left(k_{1}, k_{2}, \ldots, k_{n}\right)$ is closer to the optimal decision when the information is more comprehensive and transparent, it may also represent some features of the information structure of the business group.

According to (4) and (5), the dynamic decision-making process of subsidiary $i$ can be written as follows:

$$
\begin{aligned}
& a_{i, t+1}=a_{i, t}+k_{i} a_{i, t}\left[-\gamma S_{t}^{2}+\beta S_{t}+\beta a_{i, t}-2 \gamma a_{i, t} S_{t}\right. \\
& \left.-2 q_{i} a_{i, t}+\alpha-n_{i}\right] .
\end{aligned}
$$

Hence, the dynamic decision-making process of the business group can be represented by an $n$-dimensional nonlinear iterative system:

$$
\begin{aligned}
& a_{1, t+1}=a_{1, t}+k_{1} a_{1, t}\left[-\gamma S_{t}^{2}+\beta S_{t}+\beta a_{1, t}-2 \gamma a_{1, t} S_{t}\right. \\
& \left.-2 q_{1} a_{1, t}+\alpha-n_{1}\right], \\
& a_{2, t+1}=a_{2, t}+k_{2} a_{2, t}\left[-\gamma S_{t}^{2}+\beta S_{t}+\beta a_{2, t}-2 \gamma a_{2, t} S_{t}\right. \\
& \left.-2 q_{2} a_{2, t}+\alpha-n_{2}\right], \\
& \vdots \\
& a_{n, t+1}=a_{n, t}+k_{n} a_{n, t}\left[-\gamma S_{t}^{2}+\beta S_{t}+\beta a_{n, t}-2 \gamma a_{n, t} S_{t}\right. \\
& \left.-2 q_{n} a_{n, t}+\alpha-n_{n}\right] .
\end{aligned}
$$

The profit of subsidiary $i$ is $\pi_{i, t}$; thus the total profit of the business group in period $t$ can be written as follows:

$$
\pi_{t}=\sum_{i=1}^{n} \pi_{i, t}
$$

We also assume that $\widetilde{d}_{i, t}$ are independent for different subsidiaries and we define $\widetilde{d}_{t}$ as follows:

$$
\widetilde{d}_{t}=\sum_{i=1}^{n} \widetilde{d}_{i, t} .
$$

Consequently, $\widetilde{d}_{t}$ follows the uniform distribution $U[0$, $\left.2 S_{t}\right]$.

In this study, the probability of default is used to measure the credit risk of the business group. According to the fifth assumption, the default will only occur in a period when the total profit of the business group is less than its fixed financial cost. Therefore, the business group defaults if and only if the following inequality is satisfied:

$$
\pi_{t}-\sum_{i=1}^{n} C_{i, t}<D
$$

Hence, the probability of default can be written as follows:

$$
\operatorname{Pr}\left(\tilde{d}_{t}<\frac{D+\sum_{i=1}^{n} C_{i, t}}{P_{t}}\right)
$$

Since $\widetilde{d}_{t}$ follows the uniform distribution, the probability of default in period $t$ can ultimately be written as follows:

$$
\operatorname{Pr}_{t}\left(a_{t}\right)=\frac{D+\sum_{i=1}^{n} C_{i, t}}{2 S_{t} P_{t}}
$$

where $a_{t}=\left(a_{1, t}, a_{2, t}, \ldots, a_{n, t}\right)$.

Specifically, the financial cost of the business group may be due to the liabilities of its subsidiaries, and the constant $D$ measures the total financial cost of all the subsidiaries in each period. In reality, the business group often moves money to subsidiaries that face the risk of default from other subsidiaries based on its internal capital market; thus rob Peter to pay Paul. Therefore, we do not need to consider the different debt structures among the subsidiaries, and we only assume a fixed total financial cost, to simplify the model in this study.

2.3. Model Analysis. Without loss of generality, we consider the special case of $n=3$ for simplicity. Then, the dynamic decision-making process model can be constructed as the following 3-dimensional iterative system:

$$
\begin{aligned}
x^{\prime} & =x+k_{1} x\left[-\gamma S_{t}^{2}+\beta S_{t}+\beta x-2 \gamma x S_{t}-2 q_{1} x+\alpha\right. \\
& \left.-n_{1}\right], \\
y^{\prime} & =y+k_{2} y\left[-\gamma S_{t}^{2}+\beta S_{t}+\beta y-2 \gamma y S_{t}-2 q_{2} y+\alpha\right. \\
& \left.-n_{2}\right], \\
z^{\prime} & =z+k_{3} z\left[-\gamma S_{t}^{2}+\beta S_{t}+\beta z-2 \gamma z S_{t}-2 q_{3} z+\alpha\right. \\
& \left.-n_{3}\right],
\end{aligned}
$$

where $x=a_{1, t}, x^{\prime}=a_{1, t+1}, y=a_{2, t}, y^{\prime}=a_{2, t+1}, z=a_{3, t}$, and $z^{\prime}=a_{3, t+1}$. 
Therefore, the fixed points in our model satisfy the following algebraic equations:

$$
\begin{aligned}
& k_{1} x\left[-3 \gamma x^{2}-\gamma y^{2}-\gamma z^{2}-4 \gamma x y-4 \gamma x z-2 \gamma y z\right. \\
& \left.+\beta(2 x+y+z)-2 q_{1} x+\alpha-n_{1}\right]=0, \\
& k_{2} y\left[-3 \gamma y^{2}-\gamma x^{2}-\gamma z^{2}-4 \gamma y z-4 \gamma x y-2 \gamma x z\right. \\
& \left.\quad+\beta(2 y+x+z)-2 q_{2} y+\alpha-n_{2}\right]=0, \\
& k_{3} z\left[-3 \gamma z^{2}-\gamma x^{2}-\gamma y^{2}-4 \gamma y z-4 \gamma x z-2 \gamma x y\right. \\
& \left.\quad+\beta(2 z+x+y)-2 q_{3} z+\alpha-n_{3}\right]=0 .
\end{aligned}
$$

In the dynamic decision-making process, parameters $\alpha, \beta, \gamma, m_{i}, n_{i}, q_{i}, D$ are relatively fixed whereas the adjustment coefficients $k_{i}$, which depend on the specific characteristics of the subsidiaries, are not. In order to make the study convenient, we fix the parameters as follows:

$$
\begin{aligned}
\alpha & =5, \\
\beta & =0.5, \\
\gamma & =1, \\
m_{1} & =0.2, \\
n_{1} & =0.5, \\
q_{1} & =0.1, \\
m_{2} & =0.3, \\
n_{2} & =0.4, \\
q_{2} & =0.2, \\
m_{3} & =0.4, \\
n_{3} & =0.3, \\
q_{3} & =0.3, \\
D & =2 .
\end{aligned}
$$
lows:

Then, the algebraic equations (14) can be rewritten as fol-

$$
\begin{gathered}
k_{1} x\left[-3 x^{2}-y^{2}-z^{2}-4 x y-4 x z-2 y z\right. \\
+0.5(2 x+y+z)-0.2 x+4.5]=0, \\
k_{2} y\left[-3 y^{2}-x^{2}-z^{2}-4 y z-4 x y-2 x z\right. \\
\quad+0.5(2 y+x+z)-0.4 y+4.6]=0, \\
k_{3} z\left[-3 z^{2}-x^{2}-y^{2}-4 y z-4 x z-2 x y\right. \\
\quad+0.5(2 z+x+y)-0.6 z+4.7]=0 .
\end{gathered}
$$

There are six fixed points: $w_{1}(0,0.8374,0.8176)$, $w_{2}(0.6160,0.6095,0.6037), \quad w_{3}(0,0,0.9416), \quad w_{4}(0,0$, $-6.8386), w_{5}(0,0,0)$, and $w_{6}(-0.4405,-0.5008,-0.5693)$. According to the algebra, we can easily show that the equilibrium and the adjustment coefficients are independent. In our model, the nonpositive equilibrium solutions are meaningless. Thus, only $w_{2}(0.6160,0.6095,0.6037)$ is the Nash equilibrium of the dynamic decision-making process. At the equilibrium, the probability of default is $41.02 \%$ for the business group.

In order to find the stable region of the Nash equilibrium point, we put $w_{2}$ into the Jacobian matrix and obtain the following:

$$
J=\left[\begin{array}{rrr}
-4.7734 k_{1} & -2.7045 k_{1} & -2.7045 k_{1} \\
-2.6680 k_{2} & -4.8371 k_{2} & -2.6680 k_{2} \\
-2.6356 k_{3} & -2.6356 k_{3} & -4.9049 k_{3}
\end{array}\right] .
$$

Therefore, the characteristic equation of the Jacobian matrix can be written as follows:

$$
f(\lambda)=\lambda^{3}+A \lambda^{2}+B \lambda+C,
$$

where

$$
\begin{aligned}
& A=4.7734 k_{1}+4.8371 k_{2}+4.9049 k_{3}, \\
& B=15.8738 k_{1} k_{2}+16.6937 k_{2} k_{3}+16.2851 k_{1} k_{3}, \\
& C=47.8501 k_{1} k_{2} k_{3} .
\end{aligned}
$$

According to the Routh-Hurwitz criterion, the necessary and sufficient condition for the asymptotic stability of the equilibrium point can be written as follows:

$$
\begin{aligned}
& f(1)=A+B+C+1>0, \\
& -f(-1)=A-B+C-1>0, \\
& C^{2}-1<0, \\
& \left(1-C^{2}\right)^{2}-(B-A C)^{2}>0 .
\end{aligned}
$$

Figure 1 shows the stability region of the Nash equilibrium point represented by algebraic equations (20). If the vector of the adjustment coefficients $\left(k_{1}, k_{2}, k_{3}\right)$ is in this three-dimensional region, the Nash equilibrium point will be reached after a certain number of iterations.

\section{Simulation and Complexity Analysis of the Credit Risk}

We conducted numerical simulations to understand the evolution of the credit risk in more depth. The model we constructed shows that the evolution of the credit risk is driven by the dynamic decision-making processes of the subsidiaries, which are described by algebraic equations (13). Therefore, we first focus on the dynamic decision-making process and consider a general circumstance where $k_{1}$ is free and $k_{2}, k_{3}$ are fixed. Without loss of generality, we assume that $k_{2}=0.3$ and $k_{3}=0.2$. 


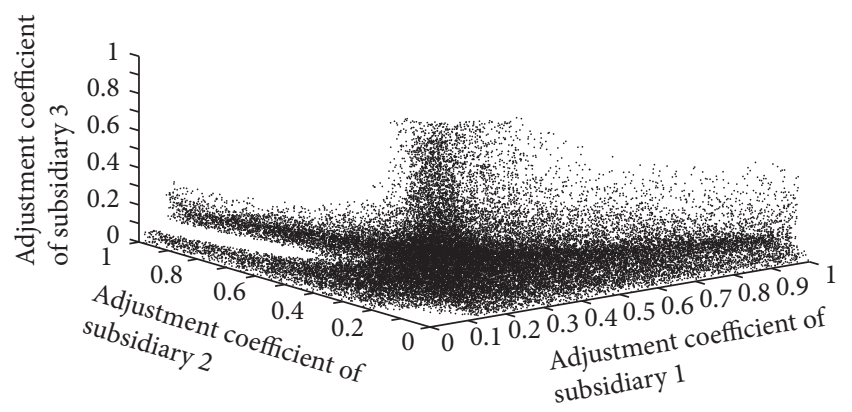

FIGURE 1: The stability region of the Nash equilibrium.

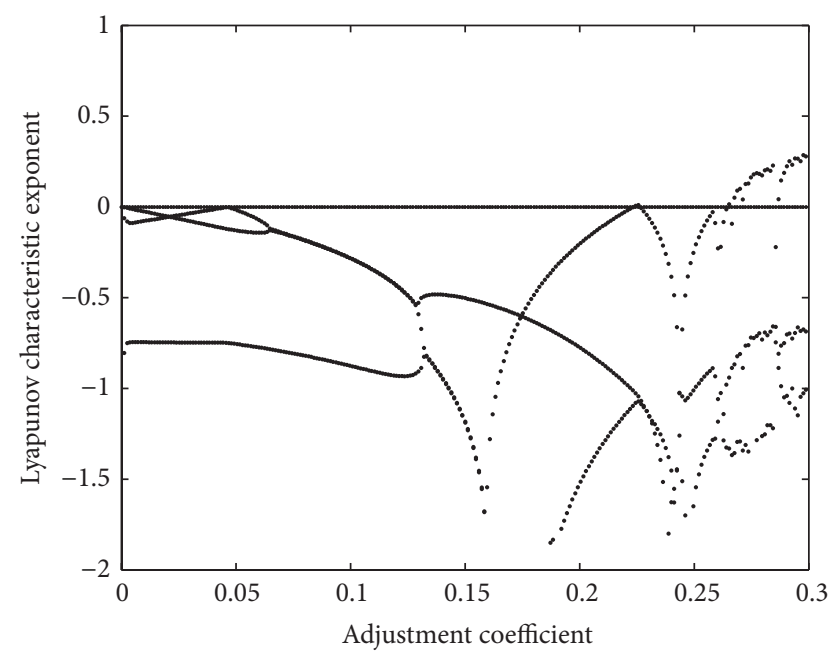

Figure 2: Lyapunov characteristic exponent of the dynamic decision-making process.

The Lyapunov characteristic exponent of a dynamical system is a commonly used quantity, which characterizes the rate of separation of infinitesimally close trajectories. The dynamic decision-making process in our model is a threedimensional dynamic system. The Lyapunov characteristic exponent in each dimension of the dynamic decision-making process is shown in Figure 2.

Figure 2 shows that the dynamic decision-making process is stable and the subsidiaries tend to select effort levels that are asymptotically equal to the Nash equilibrium point when the adjustment coefficient is $k_{1}<0.2231$. As the adjustment coefficient increases, the maximum Lyapunov characteristic exponent is always initially less than zero. Next, it equals zero, which shows that the dynamic system undergoes a period of doubling bifurcation where the oscillation is periodic. When $k_{1}>0.2865$, the maximum Lyapunov characteristic exponent becomes greater than zero, which indicates that the dynamic system has become chaotic. At this moment, the decisions made by the subsidiaries become more complex. Since the credit risk of the business group depends on these decisions, the credit risk may also become unpredictable.
To obtain a better understanding of the complex credit risk, the bifurcation shown in Figure 3 is used to describe the dynamic decision-making process and the evolution of the credit risk of the business group. Figures 3(a), 3(b), and 3(c) show the dynamic stability characteristics of decision making by the subsidiaries in the business group. The bifurcations occur as the adjustment coefficient increases. Finally, the system is chaotic. Figure 3(d) shows the bifurcation of the credit risk. According to Figure 3(d), the first bifurcation occurs at $k_{1}=0.2231$, where the probability of default is $56.21 \%$, the second bifurcation occurs at $k_{1}=0.2581$, and the third occurs at $k_{1}=0.2655, \ldots$; thus chaos emerges.

We also show the chaotic attractors of the dynamic system in Figure 4. Figures 4(a), 4(b), and 4(c) show the twodimensional chaotic attractors of the dynamic system between the credit risk and effort levels of the three subsidiaries. Figure 4(d) shows the three-dimensional chaotic attractor for the effort levels selected by three subsidiaries in the business group.

Figures 3 and 4 show that the credit risk of the business group will lead to chaos, even if the interactions among the subsidiaries are described in a very simple manner. This may explain why the credit risk of a business group is always complex and sometimes unpredictable. To illustrate the credit risk process, we use the sequence diagram of the credit risk. Figure 5 shows the changes in the credit risk over time at both $k_{1}=0.24$ and $k_{1}=0.34$. We can conclude from this figure that the credit risk of the business group changes periodically and that it can be predicted without difficulty when $k_{1}=0.24$. However, the orbit of the credit risk becomes complex as $k_{1}$ increases. It is safe to state that the chaos orbit of the credit risk will traverse all of the value sections within a specific time.

Next, we illustrate the butterfly effect of the credit risk. The chaotic system is sensitive to its initial conditions; thus we can expect that trivial differences in the initial conditions of the subsidiaries will result in departures from the evolutionary trajectories. We simulated the evolution of the credit risk of the business group with the initial conditions: $(0.3,0.2,0.3)$ and $(0.3001,0.2,0.3)$. We also calculated the difference between the credit risks with the two initial conditions over the time, as shown in Figure 6. It can be seen that the difference between the trajectories is very small and negligible at the initial stage. However, these two adjacent trajectories separate after about 20 iterations. The difference increases over time, and the adjacent trajectories are led into different domains of attraction. This figure may explain why there are many different credit risk distributions in homogeneous business groups.

In fact, if we define $k_{1}=k_{2}=k_{3}=k$ in our model, then as $k$ increases, the credit risk of the business group will reach its first stable point at $41.02 \%$. Next, it will circulate between biperiodic points, which means that there are two Nash equilibrium points in this stage. If we continue to increase $k$, the quadric-periodic phenomenon and octoperiodic phenomenon will occur in turn. According to Li and Yorke [21], the credit risk is in chaos at the quadric-periodic stage. At this time, even a tiny change in the business group can lead to the credit risk in very different directions. 


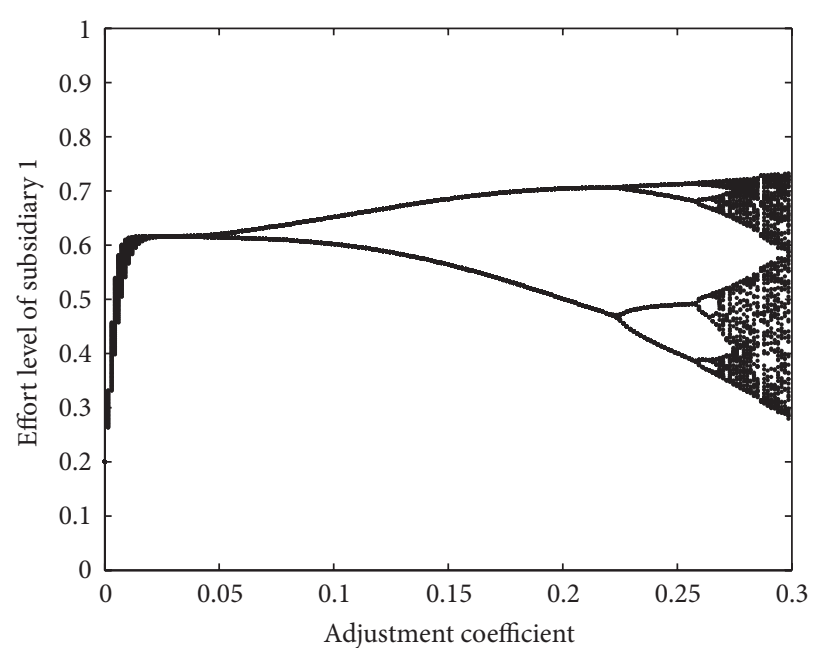

(a)

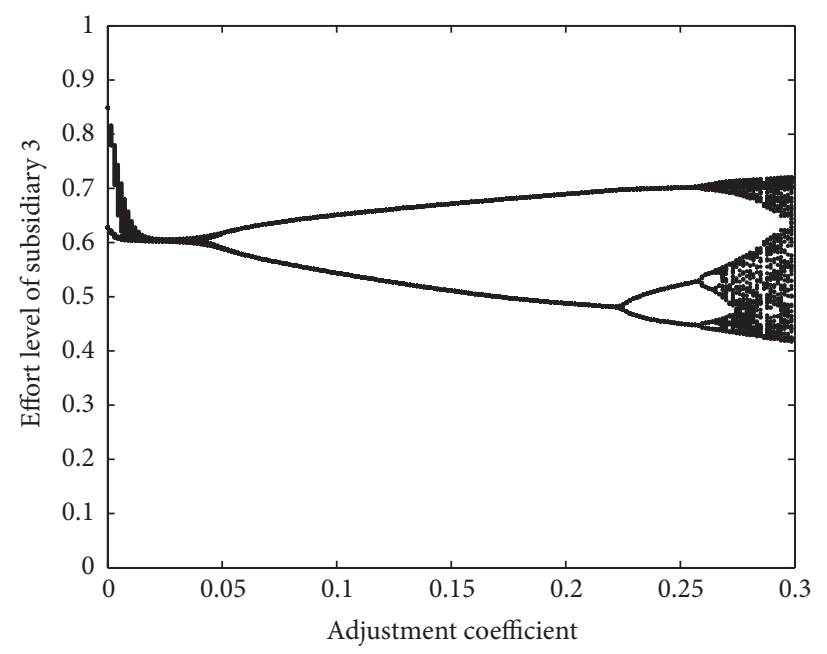

(c)

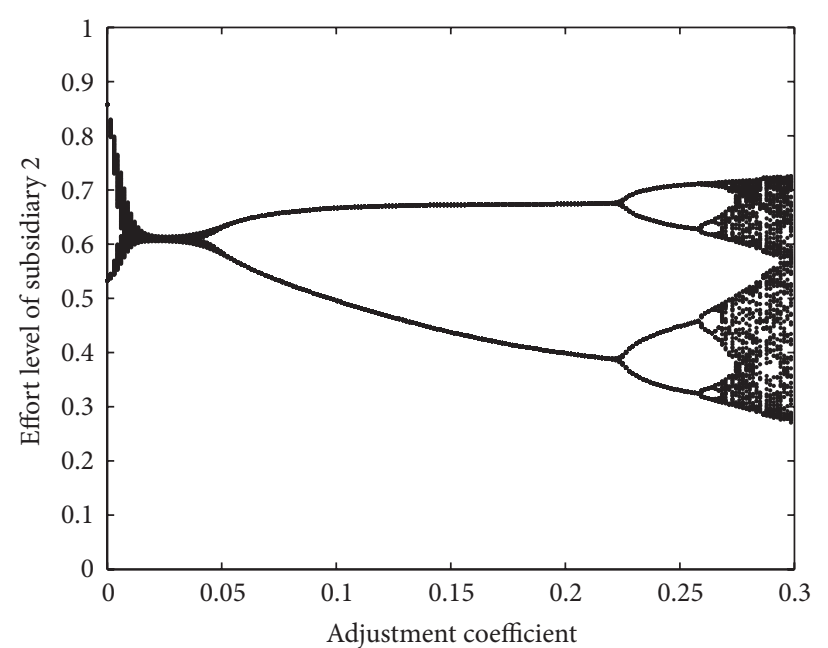

(b)

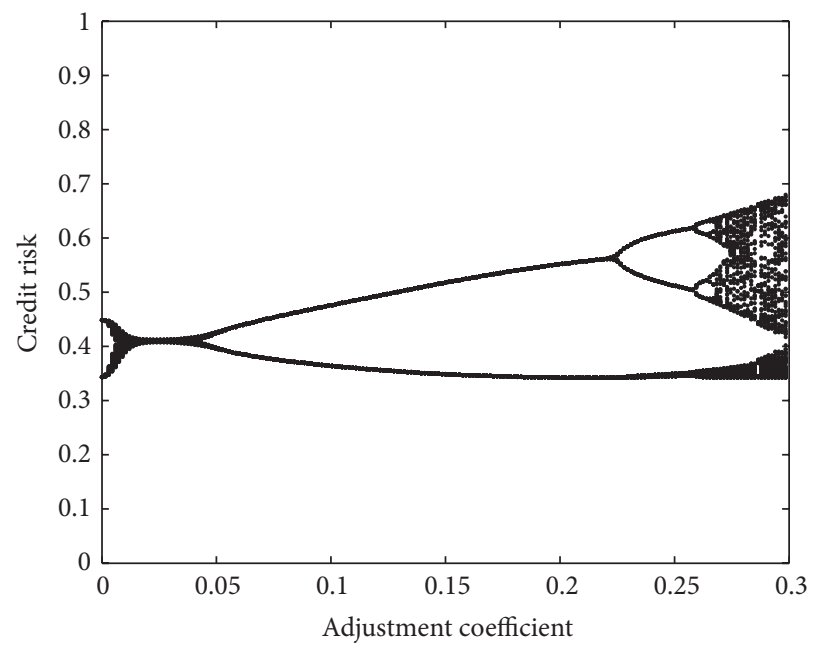

(d)

FIGURE 3: Bifurcations of the decision-making process and the credit risk.

\section{Conclusion}

Credit risk of a business group is complicated and difficult to predict compared with that of an individual company. The available literature has pointed out some of the main reasons for the complexity of credit risk of a business group. However, previous studies have not produced a formal framework that explains the mechanism behind this phenomenon. In this paper, we proposed an iterative model to describe the internal interactions and dynamic decision-making process of a business group. The credit risk of the business group was then characterized in each iteration by default probability. The subsequent stability analysis and Lyapunov characteristic exponents derived by numerical simulations have at last revealed the complexity of the credit risk of a business group. First, the credit risk of a business group might be led into chaos as time passes, even if the internal interactions of the business group were described in a fairly simple manner. Second, the flexibility of the subsidiaries, characteristics of decision makers, and information structure in a business group can all affect the Nash equilibrium of its credit risk. Lastly, the credit risk of a business group appeared to be acutely sensitive to initial conditions, and the butterfly effect was found in the evolution of the credit risk of a business group.

In this study, we have two particular contributions. First, we proposed an iterative model, which was constructed to be as concise as possible, to capture the main characteristics of the credit risk of a business group. The analysis and simulations of this model essentially revealed the complexity of the credit risk of a business group and, to some extent, explained the observed phenomenon that the credit risk of a business group is more difficult to predict than that of an individual company. Second, our results provided important theoretical insights for understanding the complexity of the credit risk of a business group, which can benefit further research in this area. In addition, this study also provided practical implications for risk control of a business group. 


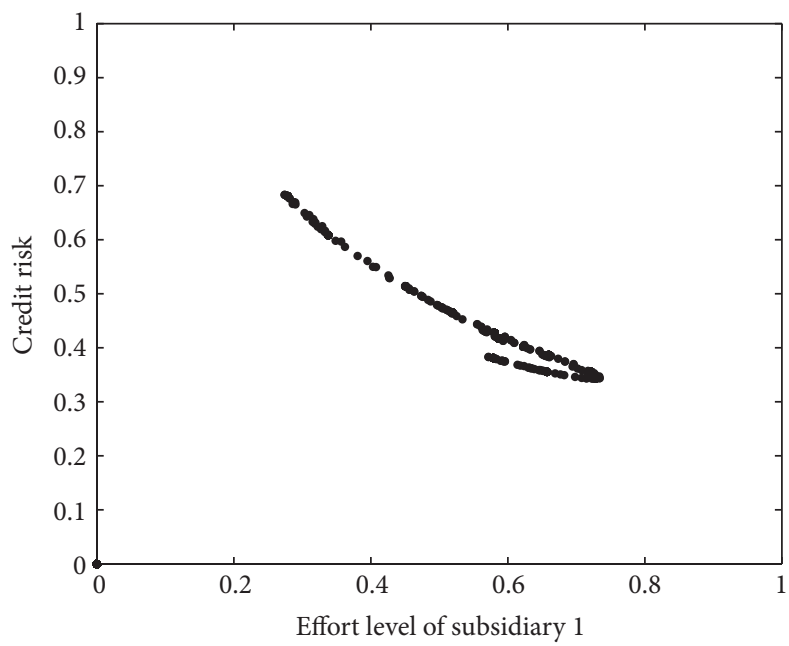

(a)

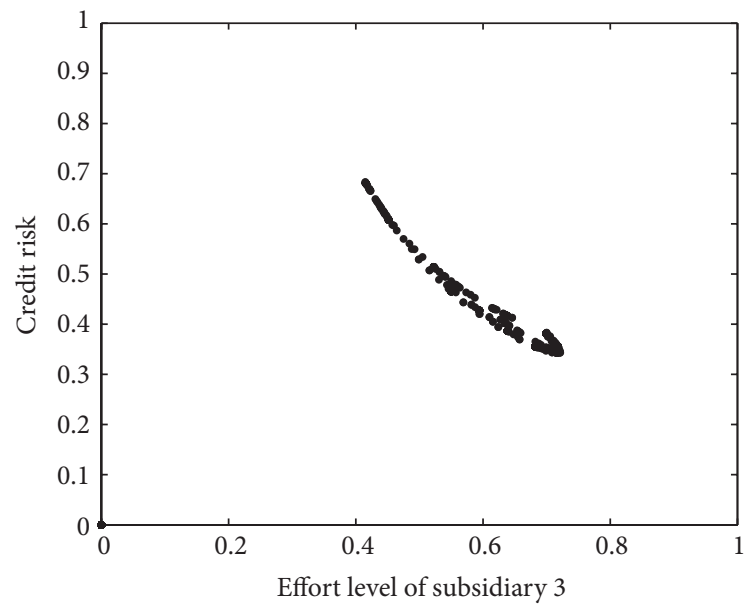

(c)

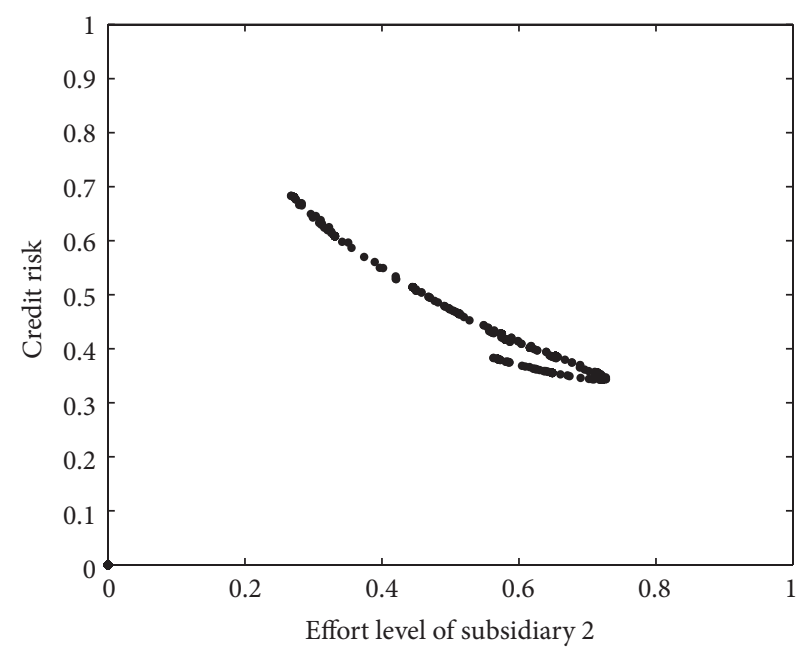

(b)

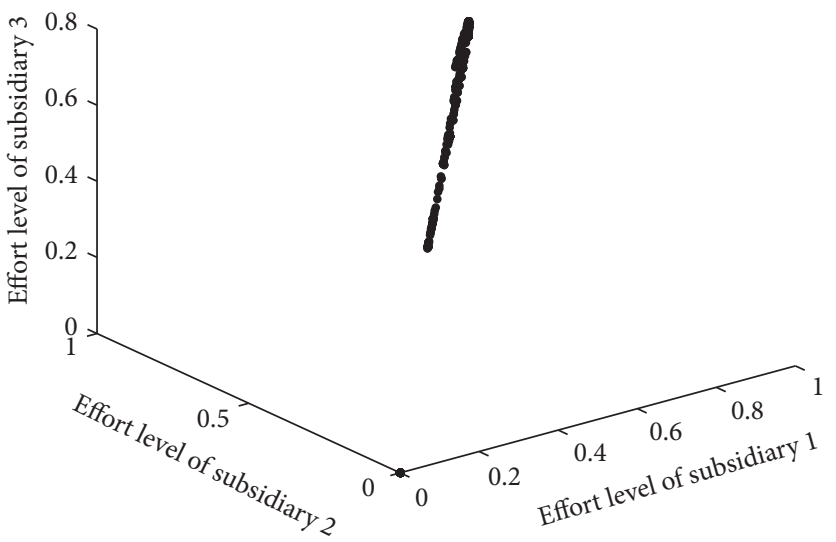

(d)

FIGURE 4: Chaotic attractors of the dynamic system.

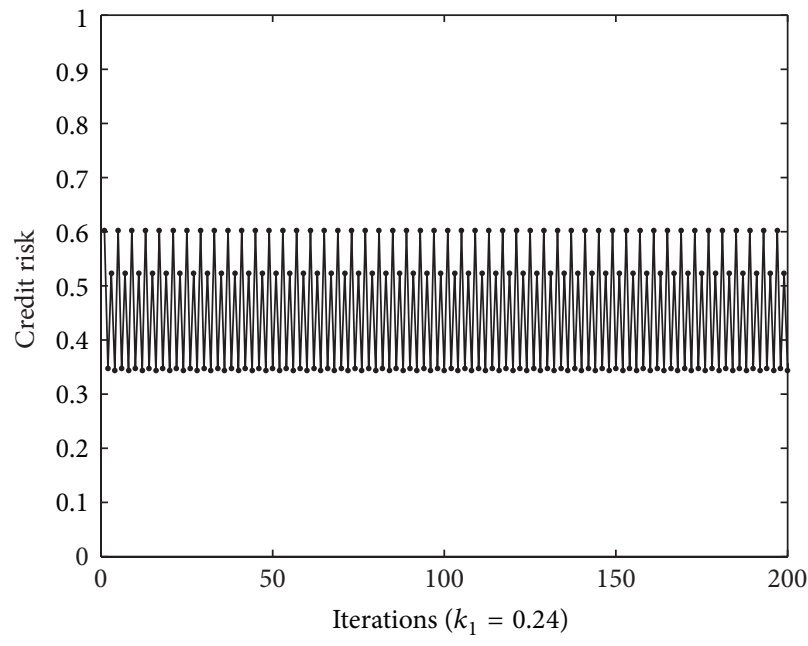

(a)

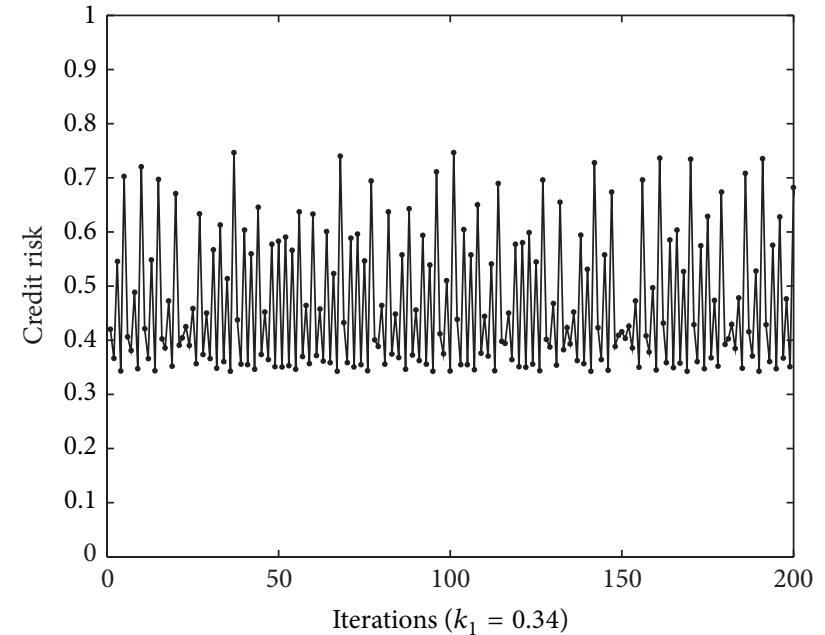

(b)

FIGURE 5: Sequence diagram showing the changes in the credit risk of the business group. 


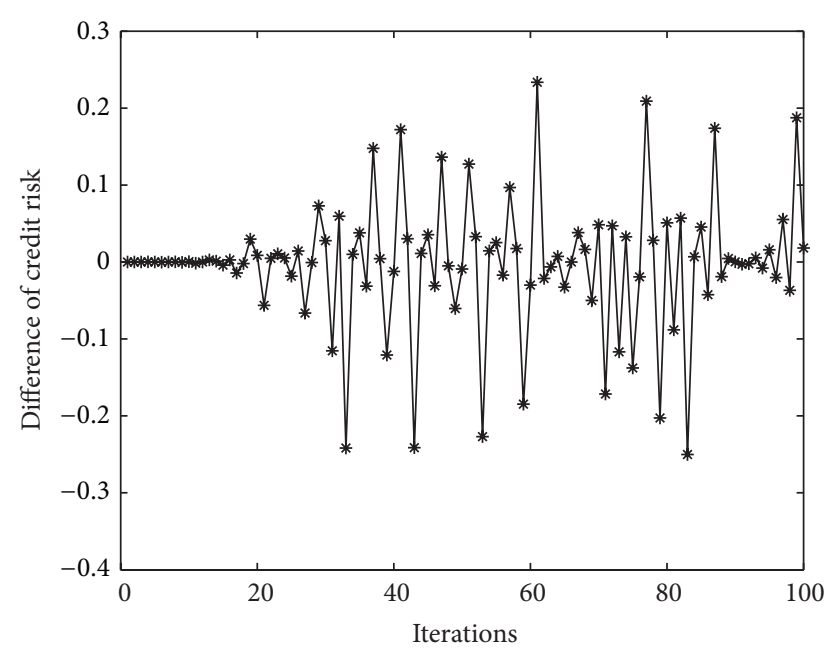

FIGURE 6: Sensitivity of the credit risk to the initial conditions.

It suggested that an appropriate internal control mechanism, information sharing, and decision process management can help to decrease the credit risk of a business group. Although the numerical simulation results in this study are based on the special case of a business group with three subsidiaries, they can easily be extended to a general circumstance involving a business group with more subsidiaries.

\section{Conflict of Interests}

The authors declare that there is no conflict of interests regarding the publication of this paper.

\section{Acknowledgments}

This research was funded by the National Natural Science Foundation of China (Approval no. 71271043 and no. 71401116) and the Specialized Research Fund for Doctoral Program of Higher Education (Approval no. 20110185110021).

\section{References}

[1] H. V. Almeida and D. Wolfenzon, "A theory of pyramidal ownership and family business groups," Journal of Finance, vol. 61, no. 6, pp. 2637-2680, 2006.

[2] T. Khanna and K. Palepu, "Is group affiliation profitable in emerging markets? An analysis of diversified Indian business groups," The Journal of Finance, vol. 55, no. 2, pp. 867-891, 2000.

[3] M. Deloof and M. Jegers, "Trade credit, corporate groups, and the financing of Belgian firms," Journal of Business Finance and Accounting, vol. 26, no. 7-8, pp. 945-966, 1999.

[4] I. Mevorach, "Appropriate treatment of corporate groups in insolvency: a universal view," European Business Organization Law Review, vol. 8, no. 2, pp. 179-194, 2007.

[5] J. Siegel and P. Choudhury, "A re-examination of tunneling and business groups: new data and new methods," Review of Financial Studies, vol. 25, no. 6, pp. 1763-1798, 2012.
[6] R. Gopalan, V. Nanda, and A. Seru, "Affiliated firms and financial support: evidence from Indian business groups," Journal of Financial Economics, vol. 86, no. 3, pp. 759-795, 2007.

[7] T. Khanna and Y. Yafeh, "Business groups and risk sharing around the world," Journal of Business, vol. 78, no. 1, pp. 301340, 2005.

[8] R. W. Masulis, P. K. Pham, and J. Zein, "Family business group around the world: costs and benefits of pyramids," Review of Financial Studies, vol. 24, pp. 3556-3600, 2011.

[9] G. Jiang, C. M. C. Lee, and H. Yue, “Tunneling through intercorporate loans: the China experience," Journal of Financial Economics, vol. 98, no. 1, pp. 1-20, 2010.

[10] S. Johnson, R. La Porta, F. Lopez-de-Silanes, and A. Shleifer, "Tunneling," The American Economic Review, vol. 90, no. 2, pp. 22-27, 2000.

[11] V. Atanasov, B. Black, C. Ciccotello, and S. Gyoshev, "How does law affect finance? An examination of equity tunneling in Bulgaria," Journal of Financial Economics, vol. 96, no. 1, pp. 155173, 2010.

[12] F. Urzua, “Too few dividends? Groups' tunneling through chair and board compensation," Journal of Corporate Finance, vol. 15, no. 2, pp. 245-256, 2009.

[13] L. Chen and Z. F. Zhou, "The research on measure default correlation of related corporations controlled by an enterprise group," Chinese Journal of Management Science, vol. 5, no. 18, pp. 159-164, 2010.

[14] T. Ané and C. Kharoubi, "Dependence structure and risk measure," The Journal of Business, vol. 76, no. 3, pp. 411-438, 2003.

[15] R. Frey and A. J. McNeil, "VaR and expected shortfall in portfolios of dependent credit risks: conceptual and practical insights," Journal of Banking and Finance, vol. 26, no. 7, pp. 13171334, 2002.

[16] G. N. F. Weiß, "Are copula-gof-tests of any practical use? Empirical evidence for stocks, commodities and FX futures," The Quarterly Review of Economics and Finance, vol. 51, no. 2, pp. 173-188, 2011.

[17] R. A. Jarrow and S. M. Turnbull, "Pricing derivatives on financial securities subject to credit risk," Journal of Finance, vol. 50, pp. 53-86, 1995.

[18] A. Y. Ha and S. L. Tong, "Contracting and information sharing under supply chain competition," Management Science, vol. 54, no. 4, pp. 701-715, 2008.

[19] J. Chen and P. C. Bell, "The impact of customer returns on supply chain decisions under various channel interactions," Annals of Operations Research, vol. 206, no. 1, pp. 59-74, 2013.

[20] G. H. Wang and J. H. Ma, "Modeling and complexity study of output game among multiple oligopolistic manufacturers in the supply chain system," International Journal of Bifurcation and Chaos, vol. 23, no. 3, Article ID 1350038, 11 pages, 2013.

[21] T. Y. Li and J. A. Yorke, "Period three implies chaos," The American Mathematical Monthly, vol. 82, no. 10, pp. 985-992, 1975. 


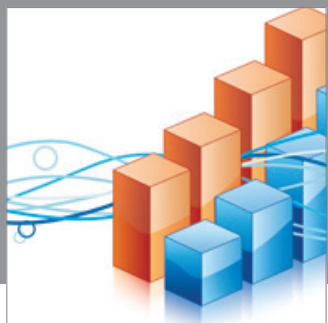

Advances in

Operations Research

mansans

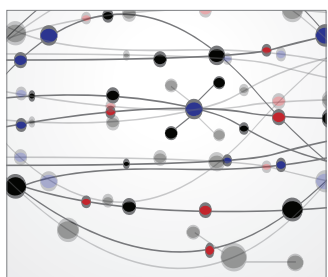

The Scientific World Journal
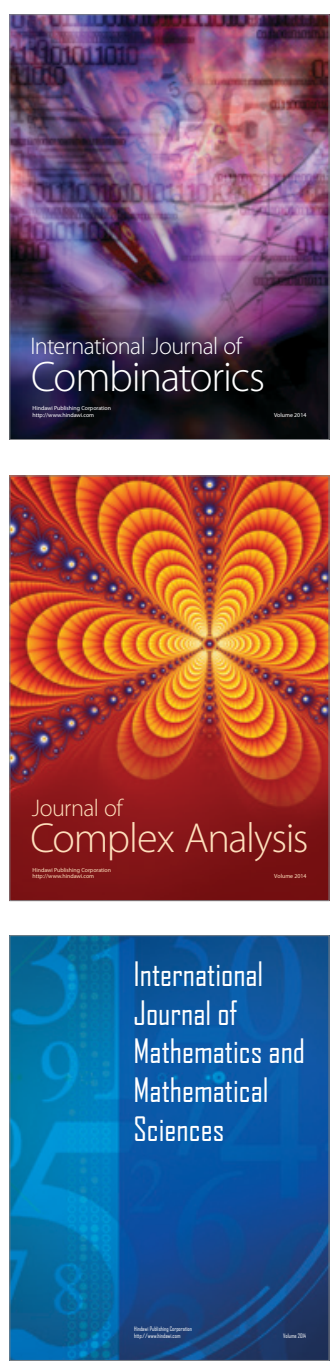
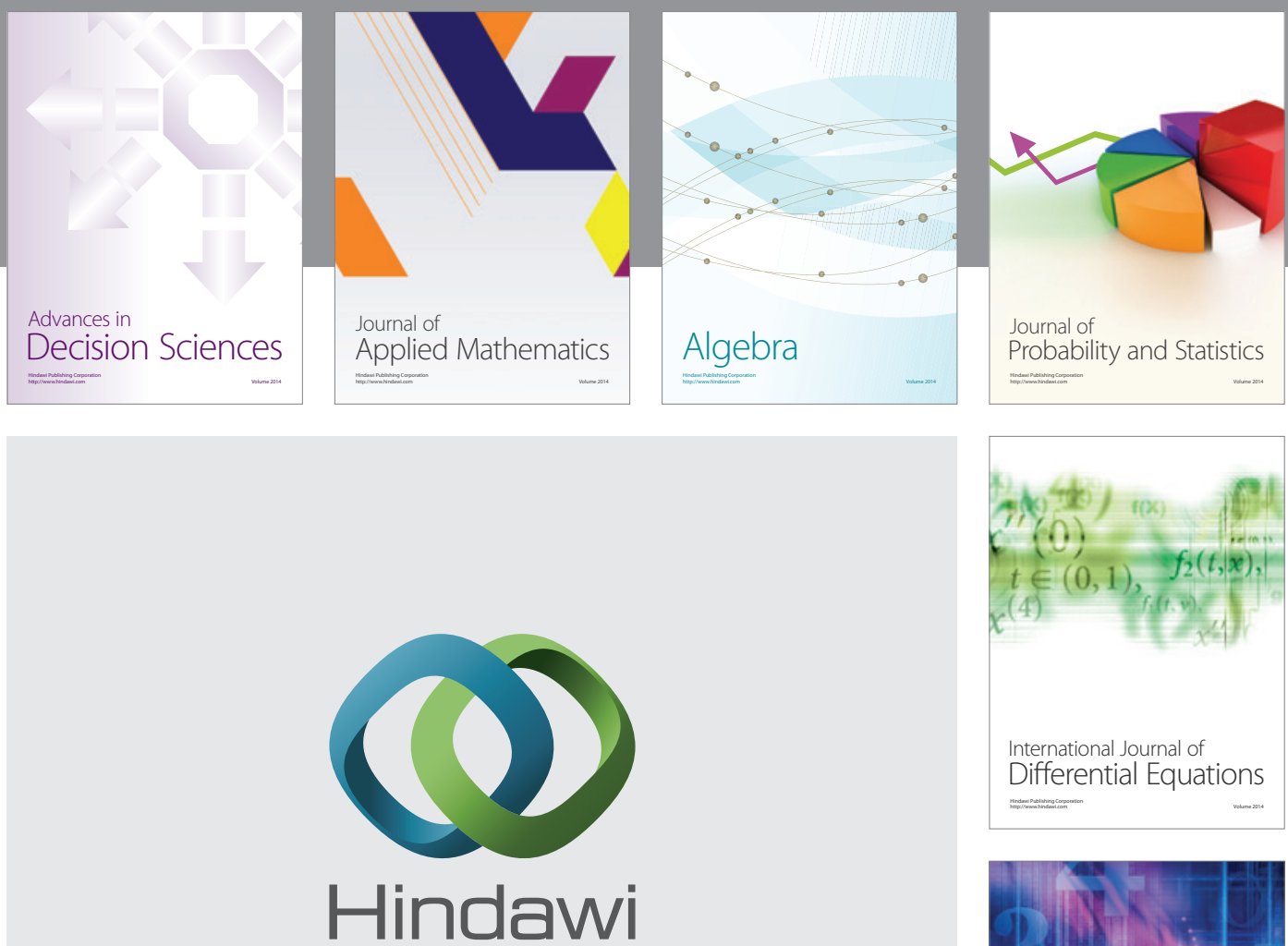

Submit your manuscripts at http://www.hindawi.com
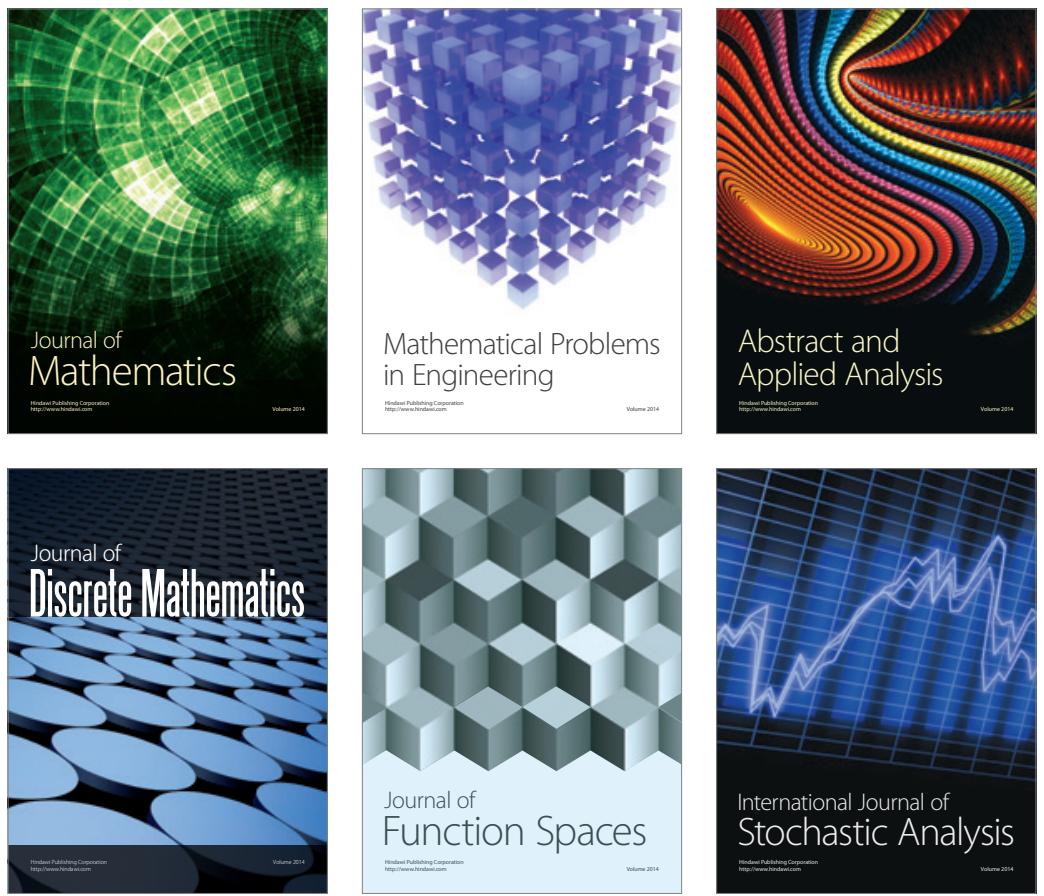

Journal of

Function Spaces

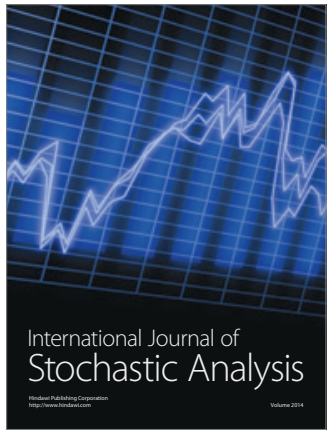

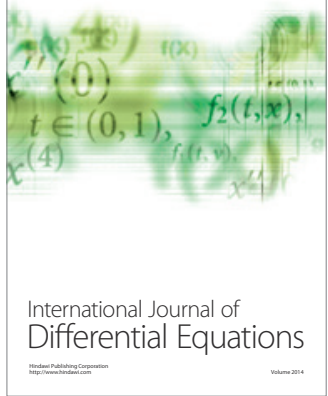
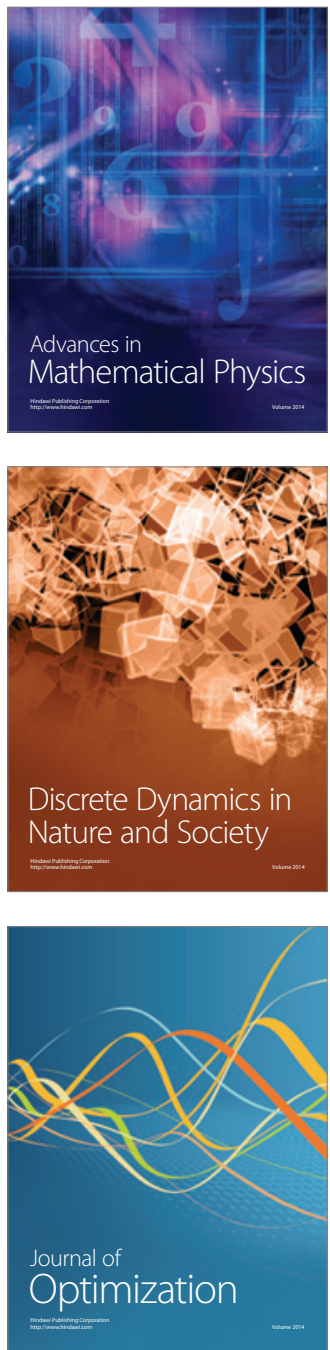